\title{
Implementasi Pendidikan Karakter Religius Melalui Pembelajaran Akidah Akhlak di Madrasah Ibtidaiyah Nurul Yaqin Kota Bogor
}

\author{
Faridatul Hasanah, Chodidjah Makarim, Kamalludin
}

Pendidikan Guru Madrasah Ibtidaiyah, Fakultas Agama Islam, Universitas Ibn Khaldun Bogor

Nenkfarida98@gmail.com, makarim.chodidjah@gmail.com, kamalludinawal66@gmail.com

\begin{abstract}
Abstrak
Tujuan Penelitian ini adalah sebagai berikut : (1. ) Untuk mengetahui ruang lingkup materi Akidah Akhlak di MI Nurul Yaqin Kota Bogor, (2). Untuk mengetahui cara apa saja yang dapat meningkatkan nilai-nilai karakter religius dikalangan MI Nurul Yaqin Kota Bogor, (3). Untuk mengetahui hambatan-hambatan yang dihadapi guru dalam mengajarkan Akidah Akhlak dalam membina karakter religius siswa di MI Nurul Yaqin Kota Bogor, (4). Untuk mengetahui metode apa saja yang bisa menerapkan pendidikan Karakter dalam Pembelajaran Akidah Akhlak, (5). Untuk mengetahui media apa saja yang bisa digunakan dalam pembelajaran Akidah Akhlak, (6) Untuk mengetahui cara penerapan pendidikan karakter melalui pembelajaran Akidah Akhlak di MI Nurul yaqin Kota Bogor. Jenis penelitian yang digunakan yaitu penelitiaan lapangan (field research) di MI Nurul Yaqin-Kota Bogor. Metode penelitiannya menggunakan kualitatif. Teknik pengumpulan data dengan observasi partisipatif, wawancara dan dokumentasi. Hasil penelitian menunjukan bahwa : 1). Ruang lingkup materi Akidah Akhlak meliputi kalimat Thayyibah, sifat-sifat Asmaul Husna, beriman kepada kitab-kitab Allah, akhlak terpuji dan akhlak tercela. 2). Cara-cara meningkatkan nilai karakter reigius, (3) mengetahui hambatan yang dihadapi guru yaitu mengurangi dan memecahkan permasaahan atau hambatan dalam belajar baik dari siswa, guru (internal) ataupun luar peserta didik (eksternal), (4) Metode yang digunakan saat pembelajaran Akidah Akhlak diantaranya yaitu ceramah, diskusi, drama atau role playing, praktek langsung atau demonstrasi dan tanya jawab. (5). Media yang dapat digunakan dalam pembelajaran Akidah Akhlak adalah media visual seperti gambar atau slide dan audio visual berupa film atau video (6) Cara penerapan pendidikan Karakter dalam pembelajaran Akidah Akhlak dapat melalui contoh sehari-hari, mengaitkan nilai karakter dengan cerita dan demonstrasi nilai karakter atau praktek langsung oleh siswa sendiri.
\end{abstract}

Kata kunci: Karakter, Religius, Akidah Akhlak 


\section{Abstract}

The objectives of this study are as follows: (1.) To find out the scope of the material of the Aqeedah in MI Nurul Yaqin Bogor City, (2). To find out what ways can improve the values of a religious character among MI Nurul Yaqin Bogor City, (3). To find out the obstacles faced by teachers in teaching the moral code in fostering the religious character of students in MI Nurul Yaqin, Bogor City, (4). To find out what methods can apply Character education in Moral Learning, (5). To find out what media can be used in learning the moral code, (6) To find out how to apply character education through learning the moral code in MI Nurul Yaqin, Bogor City. The type of research used is field research in MI Nurul Yaqin-Bogor City. The research method uses qualitative. Data collection techniques with participatory observation, interviews and documentation. The results showed that: 1). The scope of the material morality includes the sentence Thayyibah, the attributes of Asmaul Husna, faith in the books of God, laudable morals and despicable morals. 2). Ways to improve the value of religious character, (3) find out the obstacles faced by teachers, namely reducing and solving problems or obstacles in learning both from students, teachers (internal) or outside students (external), (4) The method used when learning Akidah Akhlak including lectures, discussions, drama or role-playing, direct practice or demonstrations and questions and answers. (5). Media that can be used in the study of moral code is visual media such as pictures or slides and audiovisual in the form of film or video (6) How to get character education in learning moral code can through daily examples, linking character values with stories and demonstrations of character values or direct practice by students themselves.

Keywords: Character, Religious, Akidah Akhlak

\section{PENDAHULUAN}

Pendidikan karakter pada zaman sekarang sangatlah penting. Karena sudah banyak budaya-budaya asing yang telah memasuki bangsa indonesia yang dapat merusak karakter para penerus bangsa kita. Sesuai dengan pernyataan di dalam Undang-undang Sistem Pendidikan Nasional (Sisdiknas) Nomor 20 Tahun 2003, Bab I Pasal I menyatakan bahwa "Pendidikan adalah usaha dasar dan terencana untuk mewujudkan suasana belajar dan proses pembelajaran agar peserta didik secara aktif mengembangkan potensi dirinya untuk memiliki kekuatan spiritual keagamaan, pengendalian diri, kepribadian, kecerdasan, akhlak mulia, serta keterampilan yang diperlukan dirinya, masyarakat, bangsa dan negara"1.

Pendidikan karakter sangatlah umum. Oleh karena itu, penulis memberikan penekanan dimana pendidikan karakter yang penulis tekankan yakni 'Reigius" yang terdapat pada pembelajaran Akidah Akhlah. Salah satu alasan penelitian ini diambil dari karakter Religius adalah karena minimnya sifat religius pada zaman ini karena sudah terbawanya dengan budaya asing yang mulai berdatangan ke negara Indonesia ini.

Hal ini ditegaskan oleh Prof. Dr. Muchlas Sumani dalam bukunya tentang religius : Jika wacana tentang agama yang pada esensinya adalah keyakinan

\footnotetext{
${ }^{1}$ Megawati (Depdiknas) Megawati, “UndangUndang Sistem Pendidikan Nasional” (2016).
} 
adanya Tuhan, disini buanlah menajdi alasan. Karena ternyata bertuhan atau beragama telah menjadi fitrah manusia dan tentu saja termasuk manusia yang ada di negara Indonesia ini yang dapat dilacak dalam sejarah budaya tentang asal kata Tuhan. ${ }^{2}$

Dari penjelasan diatas, sifat Religius yang akan diangkat dalam judul skripsi ini bukan hanya dilihat dari adanya Tuhan saja. Untuk mewujudkan peserta didik yang berkarakter, diperlukan pembiasaan-pembiasaan di sekolah sebagai manifestasi dari pendidikan karakter itu sendiri. ${ }^{3}$

Pendidikan karakter melalui pembelajaran Akidah Akhlak terhadap peserta didik belum tertanam atau tumbuh dalam diri peserta didik sepenuhnya, karena banyak pembelajaran yang dilakukan hanya sebagai formalitas tanpa substansi dan makna dari pembelajaran itu sendiri, serta kurangnya sumber daya manusia di sekolah, seperti guru yang kurang memadai dalam pemahaman dan yang lainnya sehingga dalam pelaksanaannya dinilai kurang efektif. ${ }^{4}$ Oleh karena itu perlu adanya pembinaan dari guru

\footnotetext{
${ }^{2}$ Muchlas Samani, Konsep Dan Model Pendidikan Karakter (Bandung: Remaja Rosdakarya, 2013).

${ }^{3} \mathrm{~K}$ Umam, K Kamalludin - Fikrah: Journal of Islamic Education, and undefined 2018, "ANALISIS NILAINILAI PENDIDIKAN ISLAM DALAM LIRIK LAGU RHOMA IRAMA," Jurnalfai-Uikabogor.Org, accessed January 23, 2020, https://www.jurnalfaiuikabogor.org/index.php/fikrah/article/view/264. ${ }^{4}$ S Asmahasanah, M Sa'diyah - Sekolah Dasar: Kajian Teori dan, and undefined 2018, "Analisis Keterampilan Mengajar Guru Dan Penanaman Nilai Positif Melalui Pemanfaatan Kebun Sekolah," Journal2.Um.Ac.Id, accessed January 23, 2020, http://journal2.um.ac.id/index.php/sd/article/vie w/1892.
}

tentang pendidikan karakter peserta didik melalui kegiatan kegamaan yang ada serta pembiasaan-pembiasaan yang dilaksanakan setiap hari di sekolah.

\section{METODE PENELITIAN}

Metode dalam penelitian ini bersifat deskriptif dengan pendekatan kualitatif. Teknik pengumpulan data menggunakan wawancara yaitu kepada Kepala Sekolah dan guru Akidah Akhlak serta guru PKN sebagai referensi nilainilai karakter. Selain wawancara penelitian ini menggunakan dokumentasi sebagai dokumen tentang laporan kegiatan pembelajaran Akidah Akhlak dan data yang berkaitan dengan pembelajaran tersebut.

Wawancara menurut KBBI adalah pertemuan tanya jawab direksi (kepala personalia, kepala humas) perusahaan dengan pelamar pekerjaan, atau bisa juga berarti pertemuan tanya jawab peneliti dengan informan untuk tanya jawab, seperti antara majikan dan orang yang melamar pekerjaan. ${ }^{5}$

Berdasarkan pengertian di atas, wawancara yang dapat dilakukan oleh peneliti yaitu wawancara langsung dengan Kepala Sekolah, Wali Kelas IV A dan IV B serta guru pelajaran Akidah Akhlak kelas IV dan guru PKN sebagai konfirmasi keselarasan antara pendidikan karakter di pembelajaran Akidah Akhlak di MI Nurul Yaqin Bogor Utara Kota Bogor karna ada bagianbagian yang relevan. Dengan tujuan

\footnotetext{
${ }^{5}$ Kumalasari Anna, Lolos Jebakan Tes Wawancara Kerja (Yogyakarta: Buku Pintar, 2012).
} 
memperoleh data terkait pelaksanaan implementasi pendidikan karakter melalui pembelajaran Akidah Akhlak yang diselenggarakan oleh lembaga pendidikan tersebut. Adapun pedoman wawancara yang akan digunakan oleh peneliti yaitu wawancara tidak struktur karena bentuk jawaban tidak terbatas akan tetapi jawaban dapat lebih banyak dibandingkan pewawancara.

Dokumentasi

Dokumen merupakan catatan peristiwa yang sudah berlalu. Dokumen tersebut dapat berupa tulisan, gambar atau karya-karya monumental dari seseorang. ${ }^{6}$

Dari pengertian di atas, dokumentasi ini digunakan untuk memperoleh data dokumen tentang laporan kegiatan pembelajaran Akidah Akhlak dan data yang berkaitan dengan pembelajaran tersebut. Dokumentasi yang akan diambil oleh peneliti dalam penelitian ini adalah dokumentasi ketika kegiatan pembelajaran Akidah Akhlak sedang berlangsung dan ketika proses wawancara.

Teknis Analisis Data

Analisis data adalah proses
mencari dan menyusun secara
sistematis data yang diperoleh dari hasil wawancara, catatan lapangan, dan dokumentasi, dengan cara mengorganisasikan data ke dalam kategori, menjabarkan ke dalam unitunit, melakukan sintesa, menyusun

\footnotetext{
${ }^{6}$ Sugiyono, Metode Penelitian Pendidikan (Pendekatan Kuantitatif, Kualitatif, Dan R\&D) (Bandung: Alfabeta, 2013).
}

kedalam pola, memilih mana yang penting dan yang akan dipelajari, dan membuat kesimpulan sehingga mudah dipahami oleh diri sendiri maupun orang lain. ${ }^{7}$

Metode analisa yang digunakan adalah metode deskriptif. Tujuannya adalah untuk menyajikan deskriptif secara sistematis dan akurat mengenai fakta-fakta, sifat serta hubungan fenomenan yang diselidiki. Dengan demikian analisis ini dilakukan saat peneliti berada dilapangan dengan cara mendeskripsikan segala data yang telah didapat, lalu dianalisis sedemikian rupa secara sistematis, cermat dan akurat.

\section{HASIL DAN PEMBAHASAN}

Penelitian ini dilakukan melibatkan guru-guru yang berkaitan dengan Akidah Akhlak. Adapun ruang lingkup Akidah Akhlak di kelas IV adalah kalimat Thayyibah, sifat-sifat Asmaul Husna, beriman kepada kitabkitab Allah, akhlak terpuji dan akhlak tercela. Cara-cara meningkatkan nilai karakter reigius dapat menggunakan cara membiasakan setiap hari sebelum memulai dan mengakhiri pembelajaran dengan membaca do'a, berdo'a setiap selesai shalat guna berserah diri kepada Allah SWT, dan mengikuti pengajian diluar sekolah. Selain itu ada hambatanhambatan yang dihadapi oleh guru yaitu mengurangi dan memecahkan permasaahan atau hambatan dalam belajar baik dari siswa, guru (internal) ataupun luar peserta didik (eksternal).

\footnotetext{
${ }^{7}$ Sugiyono.
} 
Metode yang digunakan saat pembelajaran Akidah Akhlak diantaranya yaitu ceramah, diskusi, drama atau role playing. Menurut Miftahul Huda Role Playing termasuk metode pembelajaran pengembangan imajinasi dan penghayatan dilakukan siswa dengan memerankan diri sebagai tokoh hidup atau benda mati8. Permainan ini dilakukan pada umumnya lebih dari satu orang. Titik tekan Role Playing terletak pada keterlibatan emosional dan pengamatan indra ke dalam suatu situasi permasalahan yang secara nyata dihadapi. Siswa dilakukan sebagai subjek pembelajaran yang secara aktif melakukan praktik-praktik berbahas bersama teman-temannya pada situasi tertentu. Selain role playing pembelajaran Akidah AKhlak dapat melakukan metode praktek langsung atau demonstrasi dan tanya jawab.

Media yang dapat digunakan dalam pembelajaran Akidah Akhlak adalah media visual seperti gambar atau slide dan audio visual berupa film atau video karna apabila hanya menggunakan media visual saja, siswa akan merasakan kejenuhan didalam kelas selama pembelajaran. Untuk itu guru Akidah Akhlak menerapkan media audio visual juga dalam pembelajaran Akidah Akhlak di kelas.

Dari hasil wawancara yang di dapatkan melalui Kepala Sekolah, guru Akidah Akhlak dan guru PKN dapat diketahui bahwa cara penerapan pendidikan Karakter dalam pembelajaran Akidah Akhlak dapat

\footnotetext{
${ }^{8}$ Miftahul Huda, Model-Model Pengajaran Dan Pembelajaran (Yogyakarta: Pustaka Pelajar, 2014).
}

melalui contoh sehari-hari, mengaitkan nilai karakter dengan cerita seperti cerita Masyitah mengenai sifat religius yaitu bertawakkal kepada Allah SWT dan demonstrasi nilai karakter atau praktek langsung oleh siswa sendiri seperti shalat berjamaah, berzikir dan menyebut asmaul husna (nama-nama Allah SWT) setiap sehabis shalat.

\section{SIMPULAN}

Dari hasil penelitian ini, pendidikan karakter merupakan upaya dalam menciptakan sekolah untuk mengembangkan peserta didik dalam nilai-nilai etika di sekolahnya. Pendidikan karakter sendiri merupakan salah satu tujuan dalam pendidikan, Karena tujuan dapat menentukan setiap gerak, langkah, dan aktifitas dalam proses pendidikan. Dari penelitian ini dapat diperoleh gambaran bahwa sebagian besar internal (guru, siswa) memiliki kebijakan mengenai pendidikan karakter terutama dalam penerapannya dan cara untuk meningkatkannya.

Berdasarkan uraian penelitian diatas dapat dipahami beberapa hal, pertama mengenai ruang lingkup Akidah Akhlak yang sangat berkaitan dengan nilai religius. Kedua dalam hambatan-hambatan yang dialami guru untuk memudahkan proses pembelajaran Akidah Akhlak. Ketiga upaya meningkatkan nilai religius dikalangan siswa harus bisa lebih diperhatikan kembali baik dari guru ataupun siswa. Keempat metodemetode yang digunakan haruslah dapat membentuk aspek nilai-nilai karakter agar dapat mencapai tujuan 
pembelajaran tersebut. Kelima media yang digunakan juga tidak monoton dan menarik perhatian siswa agar tidak jenuh seperti audio visual. Dan keenam mengenai penerapan pendidikan karakter melalui pembelajaran Akidah Akhlak seperti mengaitkan nilai-nilai karakter didalam pembelajaran. Contohnya berdo'a sebelum dan sesudah belajar dan jujur ketika mengerjakan soal.

\section{SARAN}

Bagi orang tua untuk lebih memberikan contoh mengenai nilai-nilai karakter khususnya religius, karna orang tua adalah contoh paling pertama kali dilihat. Juga bagi pihak sekolah untuk lebih menekankan guru-guru mengenai pendidikan karakter dalam mengajar. Bagi peseta didik untuk mempunyai akhlak yang baik dari berbagai pembelajaran di sekolah khususnya dalam pembelajaran Akidah Akhlak seperti ynag peneliti bahas kali ini. Dan yang terakhir untuk para peneliti-peneliti lainnya agar dapat meneliti lebih dalam terkait pendidikan karakter dan juga pembelajaran Akidah Akhlak.
Journal2.Um.Ac.Id. Accessed January 23, 2020.

http://journal2.um.ac.id/index.php /sd/article/view/1892.

Huda, Miftahul. Model-Model Pengajaran Dan Pembelajaran. Yogyakarta: Pustaka Pelajar, 2014.

Megawati, Megawati (Depdiknas). Undang-undang Sistem Pendidikan Nasional (2016).

Samani, Muchlas. Konsep Dan Model Pendidikan Karakter. Bandung: Remaja Rosdakarya, 2013.

Sugiyono. Metode Penelitian Pendidikan (Pendekatan Kuantitatif, Kualitatif, Dan R\&D). Bandung: Alfabeta, 2013.

Umam, K, K Kamalludin - Fikrah: Journal of Islamic Education, and undefined 2018. "ANALISIS NILAI-NILAI PENDIDIKAN ISLAM DALAM LIRIK LAGU RHOMA IRAMA." JurnalfaiUikabogor.Org. Accessed January 23, 2020. https://www.jurnalfaiuikabogor.org/index.php/fikrah/ar ticle/view/264.

\section{DAFTAR PUSTAKA}

Anna, Kumalasari. Lolos Jebakan Tes Wawancara Kerja. Yogyakarta: Buku Pintar, 2012.

Asmahasanah, S, M Sa'diyah - Sekolah Dasar: Kajian Teori dan, and undefined 2018. "Analisis Keterampilan Mengajar Guru Dan Penanaman Nilai Positif Melalui Pemanfaatan Kebun Sekolah." 